\title{
Intercalibration studies of short-lived thorium-234 in the water column and marine particles
}

Kanchan Maiti ${ }^{1,2 *}$, Ken O. Buesseler ${ }^{2}$, Steven M. Pike ${ }^{2}$, Claudia Benitez-Nelson ${ }^{3}$, Pinghe Cai ${ }^{4}, 15$, Weifang Chen ${ }^{4}$, Kirk Cochran $^{5}$, Minhan Dai ${ }^{4}$, Frank Dehairs ${ }^{6}$, Beat Gasser ${ }^{7}$, Roger P. Kelly, Pere Masque, Lisa A. Miller ${ }^{10}$, Juan Carlos Miquel7, S. Bradley Moran $^{8}$, Paul J. Morris ${ }^{2,11}$, Florian Peine ${ }^{12}$, Frederic Planchon ${ }^{6,13}$, Alisha A. Renfro ${ }^{5,14}$, Michiel Rutgers van der Loeff ${ }^{15}$, Peter H. Santschi ${ }^{16}$, Robert Turnewitsch ${ }^{17}$, James T. Waples ${ }^{18}$, and Chen $\mathrm{Xu}^{16}$

${ }^{1}$ Louisiana State University, Department of Oceanography and Coastal Sciences, Baton Rouge, Louisiana, USA

${ }^{2}$ Woods Hole Oceanographic Institution, Department of Marine Chemistry and Geochemistry, Woods Hole, Massachusetts, USA ${ }^{3}$ University of South Carolina, Department of Earth and Ocean Sciences and Marine Science Program, Columbia, South Carolina, USA ${ }^{4}$ Xiamen University, State Key Laboratory of Marine Environmental Science, Xiamen, China

${ }^{5}$ State University of New York, Stony Brook, New York, USA

${ }^{6}$ Vrije Universiteit, Brussel, Analytical and Environmental Chemistry and Earth System Sciences, Brussels, Belgium

${ }^{7}$ International Atomic Energy Agency, Environment Laboratories, Monaco

${ }^{8}$ University of Rhode Island, Graduate School of Oceanography, Narragansett, Rhode Island, USA

${ }^{9}$ Universitat Autònoma de Barcelona, Departament de Física \& Institut de Ciència i Tecnologia Ambientals, Spain

${ }^{10}$ Institute of Ocean Sciences, Fisheries and Oceans Canada, Sidney, BC, Canada

${ }^{11}$ National Oceanography Centre, Southampton, University of Southampton, Southampton, UK

${ }^{12}$ University of Rostock, Marine Biology, Rostock, Germany

${ }^{13}$ Royal Museum for Central Africa, Tervuren, Belgium

${ }^{14}$ National Wildlife Federation, New Orleans, Louisiana, USA

${ }^{15}$ Alfred-Wegener Institute for Polar and Marine Research, Bremerhaven, Germany

${ }^{16}$ Texas A\&M University, Department of Marine Sciences, Galveston, Texas, USA

${ }^{17}$ The Scottish Association for Marine Science, Dunstaffnage Marine Laboratory, Scotland, UK

${ }^{18}$ School of Freshwater Sciences, University of Wisconsin-Milwaukee, Milwaukee, Wisconsin, USA

\begin{abstract}
Intercomparision of ${ }^{234} \mathrm{Th}$ measurements in both water and particulate samples was carried out between 15 laboratories worldwide, as a part of GEOTRACES inter-calibration program. Particulate samples from four different stations namely BATS (both shallow and deep) and shelf station (shallow) in Atlantic and SAFE (both shallow and deep) and Santa Barbara station (shallow) in Pacific were used in the effort. Particulate intercalibration results indicate good agreement between all the participating labs with data from all labs falling within the $95 \%$ confidence interval around the mean for most instances. Filter type experiments indicate no significant differences in ${ }^{234} \mathrm{Th}$ activities between filter types and pore sizes $(0.2-0.8 \mu \mathrm{m})$. The only exception are the quartz filters, which are associated with $10 \%$ to $20 \%$ higher ${ }^{234} \mathrm{Th}$ activities attributed to sorption of dissolved ${ }^{234} \mathrm{Th}$. Flow rate experiments showed a trend of decreasing ${ }^{234} \mathrm{Th}$ activities with increasing flow rates $\left(2-9 \mathrm{~L} \mathrm{~min}^{-1}\right)$ for $>51 \mu \mathrm{m}$ size particles, indicating particle loss during the pumping process. No change in ${ }^{234} \mathrm{Th}$ activities on small particles was observed with increasing flow-rates. ${ }^{234} \mathrm{Th}$ intercalibration results from deep water samples at SAFe station indicate a variability of $<3 \%$ amongst labs while dissolved ${ }^{234} \mathrm{Th}$ data from surface water at Santa Barbara Station show a less robust agreement, possibly due to the loss of ${ }^{234} \mathrm{Th}$ from decay and large in-growth corrections as a result of long gap between sample collection and processing.
\end{abstract}

*Corresponding author: E-mail: kmaiti@lsu.edu

Acknowledgments

Full text appears at the end of the article.

DOI 10.4319/lom.2012.10.631
The GEOTRACES program is an international scientific collaboration focused on improving current understanding of biogeochemical cycles and large-scale distributions of trace elements and their isotopes in the marine environment. In the United States, the GEOTRACES program was initiated with a 
pair of intercalibration cruises in 2008 and 2009. Our scientific interests in this effort centered on the determination and intercalibration of the short-lived isotope, Thorium-234. The use of ${ }^{234} \mathrm{Th}$ as a flux proxy was recently reviewed and synthesized at an international workshop held in August 2004 (Benitez-Nelson and Moore [2006] and other manuscripts in Marine Chemistry volume 100[3-4]). In essence, ${ }^{234} \mathrm{Th}$ is a relatively, short-lived $\left(\mathrm{t}_{1 / 2}=24.1 \mathrm{~d}\right)$ particle reactive tracer that is produced at a constant rate from its conservative and longlived parent, Uranium-238 $\left(\mathrm{t}_{1 / 2}=4.5 \times 10^{9} \mathrm{y}\right)$. In surface waters where the vertical flux of ${ }^{234} \mathrm{Th}$ on sinking particles is large, there is a ${ }^{234} \mathrm{Th}$ deficit (i.e., total ${ }^{234} \mathrm{Th}<{ }^{238} \mathrm{U}$ ). Conversely, if the sinking particles are remineralized at depth, one can find "excess" ${ }^{234} \mathrm{Th}$ (i.e., ${ }^{234} \mathrm{Th}>{ }^{238} \mathrm{U}$ ) (Bhat et al. 1969; Coale and Bruland 1985; Buesseler et al. 1992).

In most applications, ${ }^{234} \mathrm{Th}$ is primarily used to quantify shallow export rates of sinking particles, however it is becoming increasingly evident using higher vertical resolution sampling that shallow layers of excess ${ }^{234}$ Th may be used to investigate particle remineralization rates as well (Maiti et al. 2010). Such layers have been observed in a range of environments, including regions of low particle flux, such as just below the deep chlorophyll maximum layer in the Sargasso Sea (BenitezNelson et al. 2001b; Buesseler et al. 2008; Maiti et al. 2010). ${ }^{234} \mathrm{Th}$ may also be used as a sinking flux proxy of specific elements. Whereas the most common application is for examining the export flux of particulate organic carbon (POC) (reviewed in Buesseler et al. 2006), other uses include the export flux of compounds such as surface associated organics (PAHs; PCBs- Gustafsson et al. 1997a, 1997b) and trace metals (Weinstein and Moran 2005). When used in this manner, the ${ }^{234} \mathrm{Th}$ activity balance is integrated from the surface to a given depth, and net export, $P$, is calculated on a dpm $\mathrm{m}^{-2} \mathrm{~d}^{-1}$ basis. Elemental fluxes are subsequently determined when the ${ }^{234} \mathrm{Th}$ flux, $P_{T h}$ is multiplied by its ratio to other elements (E) on sinking particles, i.e., Flux $\mathrm{P}_{\mathrm{E}}=P_{T h} \times \mathrm{E} /{ }^{234} \mathrm{Th}$ on particles, thereby providing direct information on the vertical fluxes and remineralization rates on time scales of days/weeks. When properly applied, comparisons between $\mathrm{C}$ flux derived from ${ }^{234} \mathrm{Th}$ and other independent estimates (mass balances, new production) show good agreement when integrated over appropriate time and space scales (Buesseler et al. 2006).

Given the widespread and increasing use of ${ }^{234} \mathrm{Th}$ as a particle flux tracer (Benitez-Nelson and Moore 2006, Waples et al. 2006) and the application of ${ }^{234} \mathrm{Th}$ on GEOTRACES cruises to estimate fluxes of different GEOTRACES Trace Elements and Isotopes (TEIs), it is essential that the various groups involved in ${ }^{234} \mathrm{Th}$ measurements have a comprehensive understanding of how their measurements compare. The additional information that we have gathered on the strengths and weaknesses of ${ }^{234} \mathrm{Th}$ analysis throughout this manuscript will further improve the way ${ }^{234} \mathrm{Th}$ is used to determine vertical fluxes and remineralization rates of biogeochemically relevant materials that vary on time scales of days to weeks.
The major objectives of the GEOTRACES program are to (1) determine global ocean distributions of selected trace elements and isotopes, including their concentration, chemical speciation, and physical form, and (2) evaluate the sources, sinks, and internal cycling of these species in order to characterize more completely the physical, chemical, and biological processes regulating their distributions (Henderson et al. 2007). These objectives are being met by national and international sampling efforts carried out along a number of sections in all the major ocean basins. Since GEOTRACES is an international program, many countries are, or will be, conducting their own GEOTRACES cruises. However, before this major effort can begin in earnest, it is essential that intercalibration activities take place to ensure the accuracy of all the collected data.

\section{Materials and procedures}

Intercalibration is defined by the GEOTRACES Science Plan as "The process, procedures, and activities used to ensure that the several laboratories engaged in a monitoring program can produce compatible data. When compatible data outputs are achieved and this situation is maintained, the laboratories can be said to be intercalibrated" (Taylor 1987). Thus, intercalibration is an active process between laboratories that includes all steps, from sampling to analyses, with the goal of achieving the same accurate results regardless of the method or lab. The ultimate goal for the Thorium-234 intercalibration component of GEOTRACES is to achieve the best precision and accuracy possible (lowest random and systematic errors) as a prelude to, and continuing effort throughout, the sampling and analysis program. An outcome of a relatively recent workshop on "Future Applications of ${ }^{234} \mathrm{Th}$ in Aquatic Environments" (Benitez-Nelson and Moore 2006; Waples et al. 2006; Rutgers van der Loeff et al. 2006) was an explicit need for a particulate ${ }^{234} \mathrm{Th}$ intercalibration and standards. One option would be to create an artificial ${ }^{238} \mathrm{U}^{234} \mathrm{Th}$ enriched particle/filter matrix as a standard, but the difficulty in making such as standard and the issues associated with correcting ${ }^{234} \mathrm{Th}$ activities for absorption of $\beta$ particles by differing materials would not be well addressed. An alternative solution is to collect evenly distributed natural marine particles on filters with different loading and particle characteristics from surface and deep waters as well as oligotrophic and mesotrophic regions. The latter option was thus used in the GEOTRACES ${ }^{234} \mathrm{Th}$ intercalibration effort.

To accomplish this goal, particulate ${ }^{234}$ Th material was collected using two size classes ( $>51 \mu \mathrm{m}$ and $1-51 \mu \mathrm{m})$, as recommended by Rutgers van der Loeff et al. (2006). On the $>51 \mu \mathrm{m}$ particles, samples were collected using two different filter types: 1 $\mu \mathrm{m}$ nominal quartz depth filters (QMA) filters and $0.45 \mu \mathrm{m}$ polyethersulfone membrane filters (SUPOR). A number of tests were also conducted to understand the variability associated with collection of large particles. Finally, small volume water samples (2-8 L) were also collected for intercalibration of methods used to measure dissolved and total ${ }^{234} \mathrm{Th}$ measurements. 
Fifteen different laboratories from across the world actively involved in ${ }^{234} \mathrm{Th}$ measurements accepted the invitation to participate in the intercalibration experiment (Table 1). To preserve the confidentiality of each lab and so as not to single out any particular lab, each lab was assigned a unique number ID. Throughout this manuscript the individual labs will be referred to by this pre-assigned number, which is only known to that particular lab and the coordinating lab at the Woods Hole Oceanographic Institution. Each lab was provided with small volume and particulate ${ }^{234} \mathrm{Th}$ samples described above.

\section{Sampling plan}

The GEOTRACES Intercalibration cruises were organized around two cruises with four key "Baseline Stations." The first intercalibration cruise was from May-Jun 2008 from the Bermuda Atlantic Time Series Station (BATS) to Norfolk, Virginia. The main objective was to establish BATS as a Baseline Station for repeated sampling during other phases of the GEOTRACES Program. A second mesotrophic station occurred near the shelf break proximal to Norfolk (SHELF) with the focus being on particle reactive TEIs in waters with higher particle concentrations. In June 2009, the second cruise was held in the North Pacific (Honolulu to San Diego), to occupy the SAFe (Sampling and Analysis of Iron) station $\left(30^{\circ} \mathrm{N} 140^{\circ} \mathrm{W}\right)$ where a prior Fe inter-comparison had recently been conducted (Johnson et al. 2007). This site was the second GEOTRACES Baseline Station with relatively easy access from San Diego. A second site in the Santa Barbara Basin (SBB) was also sampled, where the focus was on coastal sampling with expected higher particle loads and bottom hypoxia.

During the 2008 Atlantic cruise, only particulate samples were collected for intercalibration. Samples were collected using battery-operated McLane pumps deployed using a plastic jacketed hydrowire. To meet the large sample requirement for all the labs, an epoxy-coated aluminum frame was designed that accommodates up to 8 McLane pumps at a time (Fig. 1), thereby enabling simultaneous sampling at one depth and reducing naturally occurring spatial and temporal variability common in marine environments. Size-fractionated particulate samples were collected using $142 \mathrm{~mm}$ diameter, acid-cleaned $(10 \% \mathrm{HCl}), 51 \mu \mathrm{m}$ screen (large particles) placed in-line with either acid leached nominal $1 \mu \mathrm{m}$ QMA filter or a $0.45 \mu \mathrm{m}$ SUPOR filter (small particles). The QMA filter is the most commonly used filter type for particulate ${ }^{234} \mathrm{Th}$ measurement because it allows measurement of ${ }^{234} \mathrm{Th}$ and POC/PON on the same filter. Unfortunately, the higher metal blanks associated with QMA filter make it a less than ideal filter for analyzing elements like ${ }^{230} \mathrm{Th} /{ }^{231} \mathrm{~Pa}$ and $\mathrm{Al}$. Based on previous work demonstrating the high level of recovery, faster filtration rate, low blanks, and ease of handling (Smith et al. 1993; Cullen and Sherrell 1999; Kiene and Linn 1999) the TEI community had come to consensus to use polysulfone SUPOR filter as the filter of choice for TEI work during GEOTRACES intercalibration exercise. Because ${ }^{234} \mathrm{Th}$ can potentially be used to understand the cycling of trace metals in the upper ocean, it is imperative we test SUPOR filters along with QMA filters during this intercalibration exercise. On average, 450-600 L water was passed through QMA filters and 200-400 L water was passed through SUPOR filters. The pumps were programmed to operate within a range of 4-8 $\mathrm{L} \mathrm{min}^{-1}$.

At BATS samples were collected from multiple casts at 100 $\mathrm{m}$ and $4000 \mathrm{~m}$ for carrying out different sensitivity tests (e.g., filter types, flow rates, etc.) as well as for intercalibration between labs. Similarly, at the SHELF station repeated sampling was conducted at $\sim 100 \mathrm{~m}$ for intercalibration work. During the 2009 Pacific cruise, both particulate and water samples were collected and distributed. Water samples were collected from $4000 \mathrm{~m}$ at the SAFE station and from surface waters at the SBB station. Particulate samples were collected from 100 $\mathrm{m}$ and $\sim 4000 \mathrm{~m}$ at SAFE and from $100 \mathrm{~m}$ at SBB.

Table 1. Name of lead PI and affiliation for the participating laboratories.

Ken Buesseler
Kanchan Maiti
Claudia Benitez-Nelson
Kirk Cochran
Minhan Dai
Pere Masque
Juan Carlos Miquel
Lisa Miller
S. Brad Moran
Paul Morris
Florian Peine
Michiel Rutgers van der Loeff
Peter Santschi
Robert Turnewitsch
Jim Waples
Frank Dehair

Woods Hole Oceanographic Institution, USA

Louisiana State University, USA

University of South Carolina, USA

State University of New York, Stony Brook, USA

University Xiamen, China

Universitat Autònoma de Barcelona, Spain

International Atomic Energy Agency, Monaco

Institute of Ocean Sciences, Canada

University Rhode Island, USA

National Oceanography Centre, Southampton, UK

University of Rostock, Germany

Alfred Wegner Insitute, Germany

Texas A\&M University, Galveston, USA

Scottish Marine Institute, Scotland

University of Wisconsin, Milwaukee, USA

Virje University, Belgium 

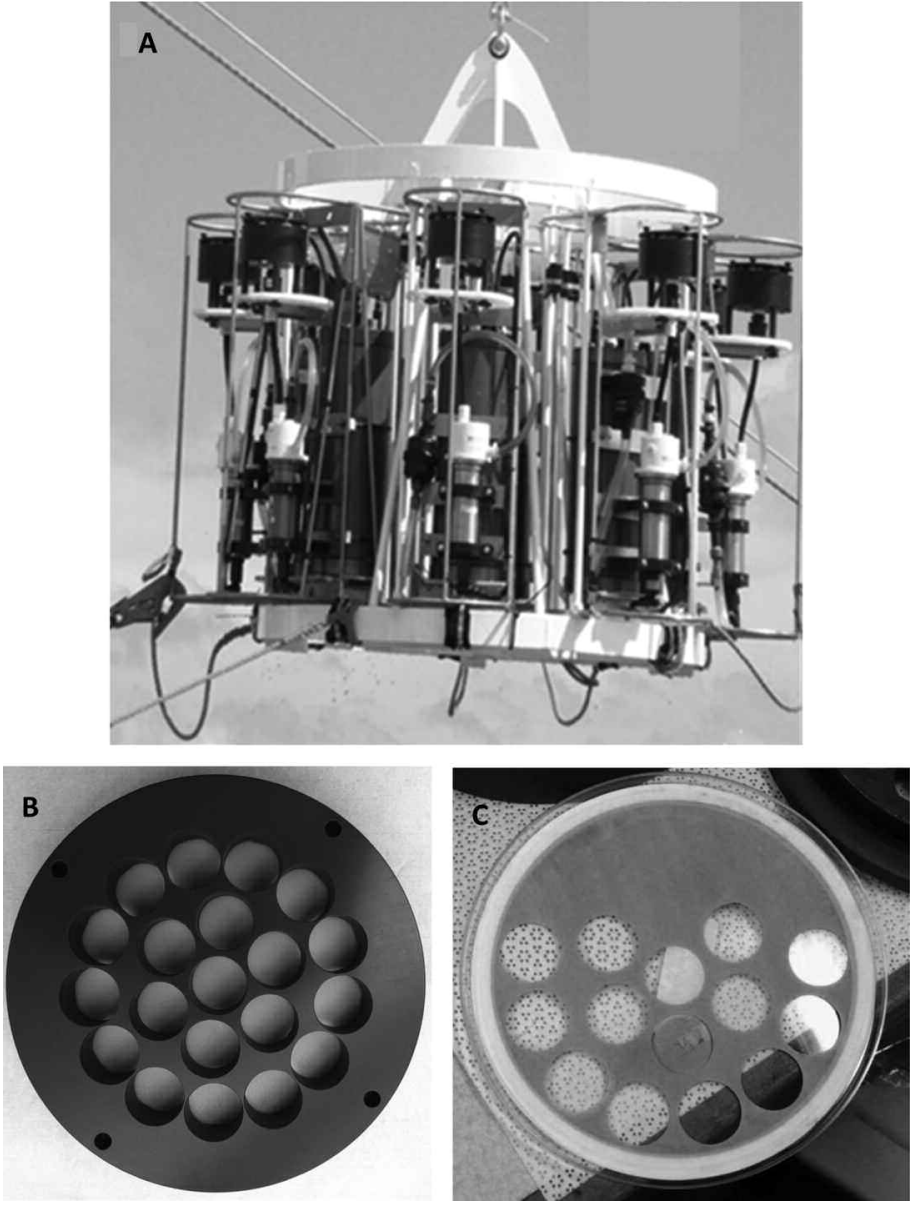

Fig. 1. Trace-metal clean 8-pump rosette (A) and PVC template (B) to subsample QMA filter (C).

All ${ }^{234}$ Th measurements were made using $\beta$ counting of the ${ }^{234} \mathrm{Th}$ daughter ${ }^{234 \mathrm{~m}} \mathrm{~Pa}\left(\mathrm{E}_{\max }=2.19 \mathrm{MeV}\right)$. A 5-position low background $\beta$ counter manufactured by RIS $\varnothing$ National Laboratories (Roskilde, Denmark) with $10 \mathrm{~cm}$ lead shield was used in this study by all laboratories except one to count the samples. One laboratory used gas-flow proportional counter with anticoincidence circuitry manufactured by $\gamma$ Products (Model G542). Samples are counted at their earliest followed by a second count after 5-6 half-lives ( 6 months) to determine backgrounds. In some laboratories, multiple counting of samples was conducted to determine the ${ }^{234} \mathrm{Th}$ decay curve over time. This allowed laboratories to discriminate between ${ }^{234} \mathrm{Th}$ and other long-lived $\beta$ emitters or background activity present in the sample. One laboratory carried out chemical purification of samples before counting them on $\beta$ detector.

\section{Assessment}

Particulate ${ }^{234} \mathrm{Th}$ intercalibration

The intercalibration of particulate samples are carried out differently for small particles collected using QMA or SUPOR filters and large particles collected using $51 \mu \mathrm{m}$ screens.

\section{Small particles}

Before the intercalibration results can be discussed, it is important to understand the inherent variability associated with initial sample collection and processing. The variability in the small particle size class $(1-51 \mu \mathrm{m})$ may arise due to inter-filter variability, i.e., the variability associated with subsamples taken from the same filter, and inter-pump variability, i.e, the variability between pumps even when they are operating simultaneously for a fixed volume with similar flow-rates.

\section{Inter-filter variability}

The inter-filter variability is a function of several processes, such as evenness of particle loading, which in turn is related to pumping system, particle nature, filter type, and subsampling. For ${ }^{234}$ Th subsampling, a PVC template was used (Fig. 1), which had 20 circular openings to punch out $22 \mathrm{~mm}$ diameter subsamples from a single $142 \mathrm{~mm}$ QMA or SUPOR filter. The average active filtration area on the QMA/SUPOR filters was measured to be $130 \mathrm{~mm}$ in diameter $(n=20)$, which translates into each $22 \mathrm{~mm}$ subsample accounting for $2.86 \%$ of the total volume filtered. To test for inter-filter variability, 20 subsamples from the same filter was collected at the BATS shallow station and analyzed by a single laboratory (WHOI). The interfilter variability for ${ }^{234} \mathrm{Th}$ on QMA and SUPOR filter punches was found to be $8.1 \%$ and $16.8 \%$, respectively (Table 2 ). This inter-filter variability represents the standard deviation between the 20 possible sub-samples without excluding any particular subsample as an outlier. POC analysis on the same QMA sub-samples had a variability of $9.8 \%$, suggesting that filter to filter variability is probably due to an uneven distribution of particles on the original $142 \mathrm{~mm}$ filter. The larger variability between the SUPOR sub-samples may be attributed to the nature of the SUPOR filter, where filtered particles are

Table 2. Comparison of inter-pump and inter-filter variability in particulate ${ }^{234} \mathrm{Th}$ activity.

\begin{tabular}{|c|c|c|c|}
\hline Filter type & Station & Inter-pump variability & Inter-filter variability \\
\hline \multirow[t]{2}{*}{ QMA } & BATS Shallow & & $8.1 \%(n=20)$ \\
\hline & SAFE Shallow & $7.8 \%(n=8)$ & \\
\hline \multirow[t]{2}{*}{ SUPOR } & BATS Shallow & $16.4 \%(n=6)$ & $16.8 \%(n=20)$ \\
\hline & SHELF & $17.9 \%(n=6)$ & \\
\hline \multirow[t]{2}{*}{ SCREEN } & SAFE Shallow & $12.5 \%(n=7) ; 11.7 \%(n=6)$ & \\
\hline & SSB & $8.3 \%(n=8) ; 8.5 \%(n=7)$ & \\
\hline
\end{tabular}


found to adhere only weakly to the filter surface, and can thus be redistributed during recovery of the pumps and opening of the filtration apparatus. It is important to note that extra precautions were taken to recover the pumps at a slower winch speed of $20 \mathrm{~m} / \mathrm{min}$. As soon as the pumps were secured onboard, the water in the headspace of the filter holders was vacuum pumped through the filter to prevent redistribution of particles before opening the filter housing. Another explanation for the higher SUPOR inter-filter variability may be in the more elastic nature of the SUPOR filters, which makes it necessary to apply force (hammering with a mallet) to the titanium punch to obtain cleanly cut subsamples. In contrast, the QMA filters can be subsampled easily by applying only light pressure to the punch. The size of the filter sub-samples may also be an important issue. When comparing the inter-filter variability between QMA and SUPOR at the BATS shallow station, the ${ }^{234} \mathrm{Th}$ variability was found to be $2 \%$ and $2.5 \%$, respectively, for larger quarter sub-samples of the filter, which represents $25 \%$ of the total filter, as opposed to the $22 \mathrm{~mm}$ punches representing only $2.86 \%$ of the total filter.

\section{Inter-pump variability}

The inter-pump variability is likely to be a combined effect of water mass heterogeneity, total volume filtered, and interfilter variability when filter subsamples are used for analysis. The inter-pump variability for the 1-51 $\mu \mathrm{m}$ particles on SUPOR punches (one from each pump analyzed by one laboratory, WHOI) was found to be $16.4 \%$ and $17.9 \%$ for the BATS and SHELF shallow stations, respectively. Although no interpump variability test for QMA filters punches was conducted at the BATS station, inter-pump variability on the QMA filters at the SAFE station (two sub-samples from each pump) was $7.8 \%$ (Table 2). Thus the inter-filter and inter-pump variability are similar for both the filter types, implying that inter-filter variability dominates the total variability.

\section{Intercalibration}

For intercalibration purposes, a single $142 \mathrm{~mm}$ filter was subsampled into individual $22 \mathrm{~mm}$ diameter punches using the above mentioned PVC template, dried, mounted on a counting disk, covered with Mylar and two-layers of aluminum foil (Buesseler et al. 2001) and distributed among the different laboratories for ${ }^{234} \mathrm{Th}$ measurement. It is important to note that the inter-filter variability of $8.1 \%$ and $16.8 \%$ for QMA and SUPOR filters, respectively, limits the extent to which the results from the different laboratories will agree with one another. The open ocean intercalibration results are shown in Figs. 2 and 3 for both the shallow and deep water stations at BATS and SAFE. The mean activity for ${ }^{234} \mathrm{Th}$ at BATS

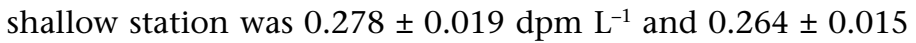
dpm $\mathrm{L}^{-1}$ for the QMA and SUPOR filters, respectively (Fig. 2). The errors on the mean activities are reported in terms of Standard Error (SE). At the SAFE shallow station the ${ }^{234} \mathrm{Th}$ activity varied from $0.280 \pm 0.017 \mathrm{dpm} \mathrm{L}^{-1}$ and $0.173 \pm 0.007 \mathrm{dpm} \mathrm{L}^{-1}$ for the QMA and SUPOR (Fig. 2). The intercalibration results from deep water samples also yielded good agreement amongst laboratories, with ${ }^{234} \mathrm{Th}$ activity of $0.077 \pm 0.007 \mathrm{dpm}$ $\mathrm{L}^{-1}$ and $0.053 \pm 0.016 \mathrm{dpm} \mathrm{L}^{-1}$ for QMA and SUPOR filters at BATS (Fig. 3) and 0.076 $\pm 0.004 \mathrm{dpm} \mathrm{L}^{-1}$ and $0.031 \pm 0.037 \mathrm{dpm}$ $\mathrm{L}^{-1}$ for QMA and SUPOR filters at SAFE (Fig. 3). Samples are also collected from higher particle regime stations at SHELF and SSB. The mean activity for ${ }^{234} \mathrm{Th}$ at SHELF shallow station

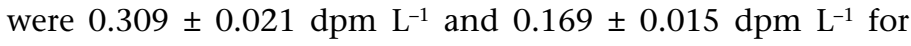
QMA and SUPOR filter while for SSB station they were $0.586 \pm$ $0.021 \mathrm{dpm} \mathrm{L}^{-1}$ and $0.501 \pm 0.032 \mathrm{dpm} \mathrm{L}^{-1}$ for QMA and SUPOR filters, respectively (Fig. 4). Overall, the QMA samples have less variability than SUPOR samples, and no significant differences between sites and water depths were noted in terms of error magnitude.

The variability in ${ }^{234} \mathrm{Th}$ activity between different laboratories and for all the intercalibration experiments is within the range of $10-15 \%$ variability observed with the inter-filter variability test. With few exceptions, the majority of the data fall within the 95\% confidence interval (dotted lines in the Figs.). The outliers do not show any consistent trends and are not associated with specific laboratories. For example, in the 2008 data set from Atlantic cruise, Lab-9 and Lab-15 have $\geq 50 \%$ of their data falling beyond the 95\% confidence limit. In contrast, for the 2009 data set from Pacific cruise Lab- 1 and Lab- 8 have $\geq 50 \%$ of the values falling beyond the $95 \%$ confidence limit. Overall, the data from all the labs compare well, and there is no consistent trend in the deviation from the calculated mean for any particular laboratory. Outliers could be due to variability associated with sampling.

\section{Large particles}

The large particles (>51) $\mu \mathrm{m}$ were collected on screens and then rinsed onto $25 \mathrm{~mm}$ silver filters using $0.1 \mu \mathrm{m}$ filtered seawater collected at $1000 \mathrm{~m}$ (Rutgers van der Loeff et al. 2006). Since the amount of material collected on the $51 \mu \mathrm{m}$ screen is too small to be shared between laboratories, discrete samples were collected from back to back casts (within 2-6 h of one another) at $100 \mathrm{~m}$ using the 8-pump rosette. Each screen was then rinsed onto a silver filter, dried, mounted on counting disk and distributed to an individual laboratory. Thus each laboratory received sample from one of the eight pumps that collected samples simultaneously. It is extremely important to understand the inter-pump variability for these samples, which again limits expectations for inter-laboratory variability for these samples.

\section{Inter-pump variability}

Due to time constraints, inter-pump variability test was not conducted on the Atlantic cruise. However during the Pacific cruise, two test casts were carried at the SAFE and SBB shallow stations to examine this issue. Samples from both the casts (seven per cast, since one pump failed in each cast) were processed on board as outlined above and counted by a single laboratory (WHOI). The mean ${ }^{234} \mathrm{Th}$ activities on the large particles were $0.016 \pm 0.002 \mathrm{dpm} \mathrm{L}^{-1}$ and $0.034 \pm 0.004 \mathrm{dpm} \mathrm{L}^{-1}$ for the two SAFE shallow station casts resulting in an interpump variability of $12.5 \%$ and $11.7 \%$, respectively, for each 

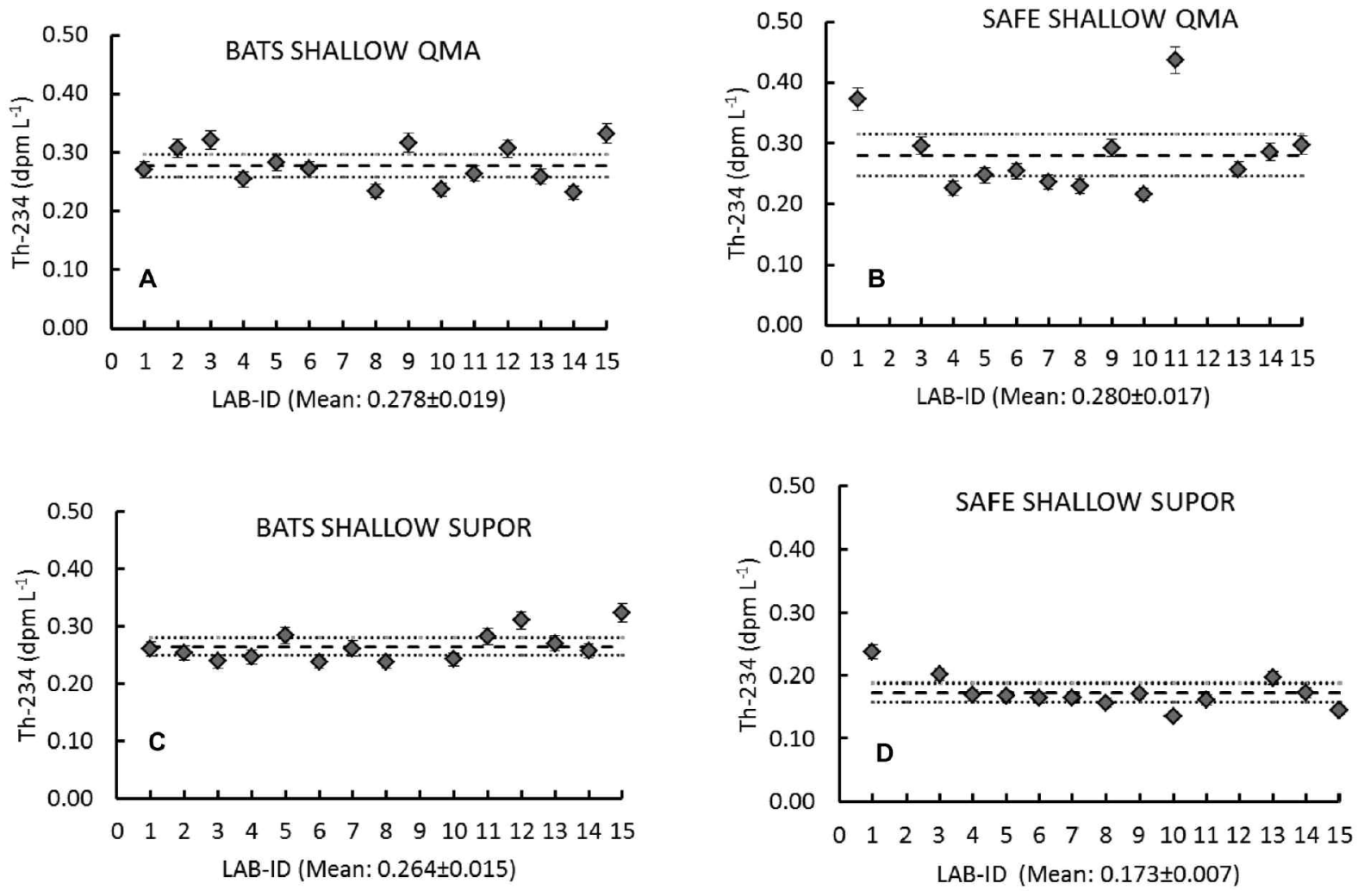

Fig. 2. Intercalibration results from open ocean shallow stations. Dotted lines represent $95 \%$ confidence interval, and dashed line represents the mean value.
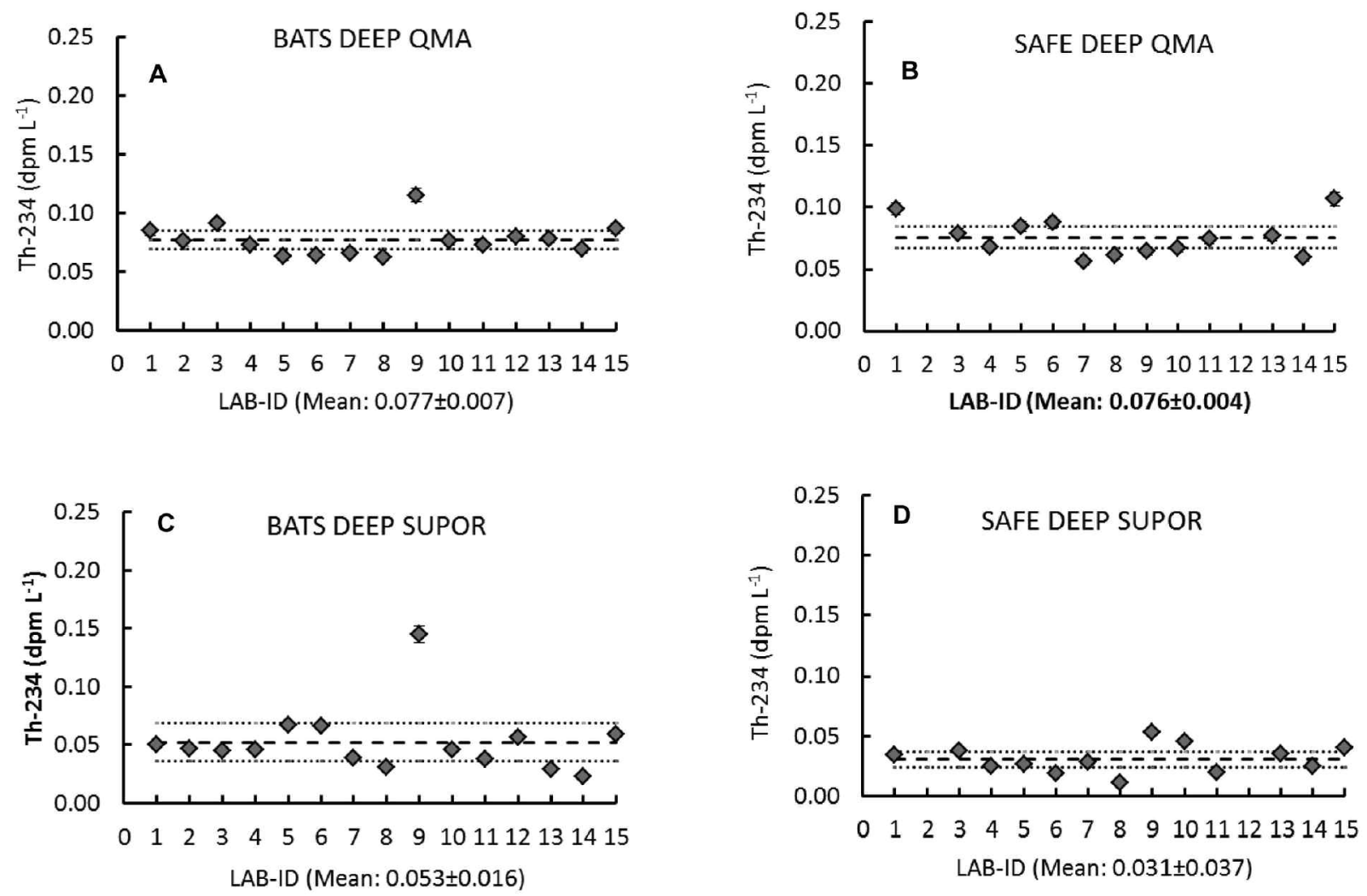

Fig. 3. Intercalibration results for open ocean deep stations. Dotted lines represent $95 \%$ confidence interval, and dashed line represents the mean value. 

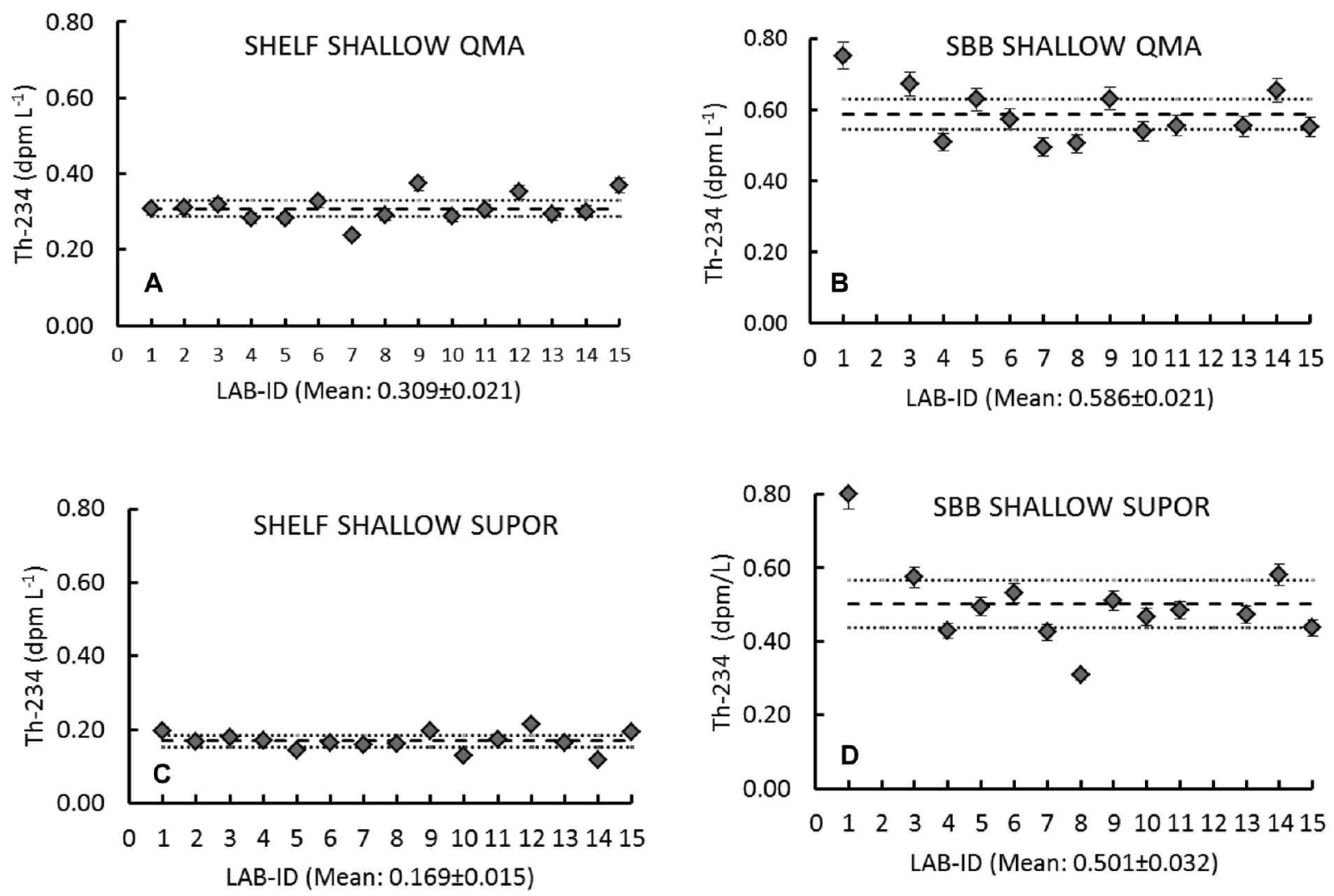

Fig. 4. Intercalibration results for near-shore shallow stations. Dotted lines represent $95 \%$ confidence interval, and dashed line represents the mean value.

cast. This difference in ${ }^{234} \mathrm{Th}$ activities between the two casts can be attributed to natural variability, as no obvious change in oceanic conditions were observed between the two casts. At the coastal SSB station, the mean ${ }^{234} \mathrm{Th}$ activities were $0.145 \pm$ $0.012 \mathrm{dpm} \mathrm{L^{-1 }}$ and $0.154 \pm 0.018 \mathrm{dpm} \mathrm{L}^{-1}$ with an inter-pump variability of $8.3 \%$ and $8.5 \%$, respectively, for each cast (Table 2 ). Thus, for the large particle inter-calibration, a variability of up to $13 \%$ can occur as a result of inherent sample to sample variability.

\section{Intercalibration}

The participating laboratories received shallow samples of large particulate material from two casts at BATS collected within $2 \mathrm{~h}$ of each other. The mean ${ }^{234} \mathrm{Th}$ activity was $0.045 \pm$ $0.002 \mathrm{dpm} \mathrm{L}^{-1}(n=8)$ and $0.018 \pm 0.002 \mathrm{dpm} \mathrm{L}^{-1}(n=7)$ for each cast (Fig. 5). At the SHELF station, three closely spaced casts were needed to collect samples for all 15 laboratories, due to multiple pump failures. The average ${ }^{234} \mathrm{Th}$ activities were $0.061 \pm 0.004 \mathrm{dpm} \mathrm{L}^{-1}(n=6), 0.063 \pm 0.004 \mathrm{dpm} \mathrm{L}^{-1}(n=4)$, and $0.035 \pm 0.002 \mathrm{dpm} \mathrm{L^{-1 }}(n=5)$ for each of the casts. Although care was taken to collect samples from different casts as close in time as possible (within 2-6 h of each other), there is always the possibility of temporal variability in water column particle concentrations between casts. Thus results from laboratories receiving samples from the same cast were only compared (Fig. 5). The variability amongst laboratories in all instances is $\sim 10 \%$, which is well within the natural variability of the collected samples. The highest variability amongst laboratories is observed for the SBB station, perhaps due to heterogeneity associated with high particle loading. Particle experiments

In addition to standard intercalibration exercise, we also conducted a number of experiments to understand the effects on particulate ${ }^{234} \mathrm{Th}$ activity by changing variables like filter type and flow rate. The samples collected for these tests were however analyzed only at WHOI.

\section{Filter type experiment}

The choice of filter used to collect the particulate fraction can impact the measured particulate ${ }^{234} \mathrm{Th}$ activity on the filters. Historically, the majority of studies used glass fiber filters (GFF, nominal pore size $0.7 \mu \mathrm{m}$ ) or QMA filters to collect particulate ${ }^{234} \mathrm{Th}$. The biggest advantage of using these filter types is that they can be used to process relatively large volumes of water without clogging, while allowing measurements of ${ }^{234} \mathrm{Th}$ and other elements such as $\mathrm{C}$ and $\mathrm{N}$, on the exact same filter. The ${ }^{234} \mathrm{Th}$ community has moved in favor of using QMA filters due to its lower radioactivity blank with direct $\beta$ counting, presumably due to a decrease in ${ }^{40} \mathrm{~K}$ present in the filter matrix (e.g., Buesseler et al. 2001). Unfortunately, a number of studies have shown that both GFF and QMA filters adsorb dissolved ${ }^{234} \mathrm{Th}$ in the water. Studies carried out by Benitez-Nel- 

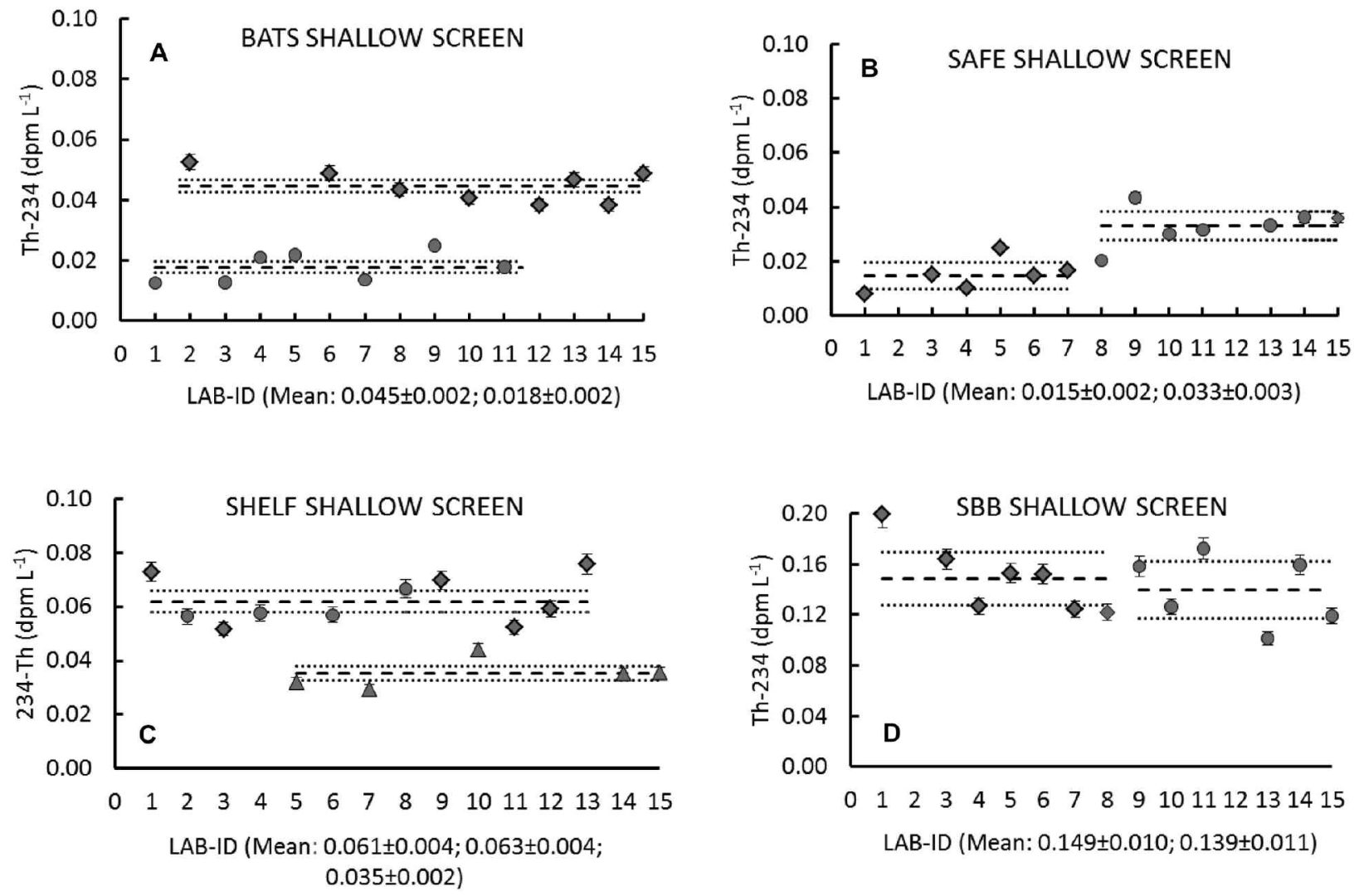

Fig. 5. Intercalibration results for large particles. Each symbol represents samples collected from a particular cast. The dashed line associated with each symbol represents the mean 234Th activity for the cast. The dotted lines represent $95 \%$ confidence interval.

son et al. (2001b) and Buesseler et al. (1998) showed that this effect was largest with small sample volumes (30-50 L as opposed to 300-500 L) and low flow rates. More recently Rutgers van der Loeff et al. (2006) carried out experiments using 2-25 L water samples from North Atlantic to demonstrate that approximately $10 \%$ to $30 \%$ of the ${ }^{234} \mathrm{Th}$ activity on the filter can be due to sorption. The present intercalibration results presented here consistently show higher ${ }^{234} \mathrm{Th}$ activity on QMA filters compared with SUPOR filters even though samples for both the filter types were collected simultaneously from the same depth.

In 2008, samples were collected at the BATS and SHELF shallow stations where five pumps on the pump rosette were loaded with a QMA filter of $1 \mu \mathrm{m}$ nominal pore size, Nuclepore, tracketched polycarbonate membranes filter of $1 \mu \mathrm{m}$ nominal pore size and SUPOR filters of $0.8 \mu \mathrm{m}, 0.45 \mu \mathrm{m}$, and $0.2 \mu \mathrm{m}$ nominal pore sizes. The pump loaded with the $0.8 \mu \mathrm{m}$ SUPOR filter at BATS and the one loaded with $0.2 \mu \mathrm{m}$ SUPOR filter at SHELF failed. The Nuclepore filter was found to be very difficult to subsample into $22 \mathrm{~mm}$ punches or quarters without compromising the sample integrity. The particles were also found to adhere much more loosely to the Nuclepore filter than the other filter types tested. Thus in spite of Nuclepore filters being very robust with low reported blanks for ${ }^{234}$ Th (Rutgers van der Loeff et al.
2006), we are unable to test this filter in our current setup and hence excluded from the comparison. The remaining available data, however, suggests that pore-size does not significantly affect the ${ }^{234} \mathrm{Th}$ activity at either station (Fig. 6). The slightly higher ${ }^{234} \mathrm{Th}$ activity on the QMA filter at the SHELF station is likely due to sorption. During the 2009 cruise, a more comprehensive test was conducted by loading different pumps in a single cast with two QMAs placed one on top of the other or "double" QMAs, SUPOR filters $(0.2,0.45,0.8$, and double $0.8 \mu \mathrm{m})$, a $0.45 \mu \mathrm{m}$ Millipore nitrocellulose membrane filter [HA], and 0.45 $\mu \mathrm{m}$ PALL mixed cellulose ester filter [GN6]. Two subsamples from each filter were analyzed for ${ }^{234} \mathrm{Th}$, and in the case of the double filters, the top and the bottom filter were counted as separate samples. The highest activity was found on the top filter of the double QMA test, while the lowest was found for the HA filter. The remaining had similar ${ }^{234} \mathrm{Th}$ activities (Fig. 6). Negligible ${ }^{234} \mathrm{Th}$ activity was found on the bottom filter of the $0.8 \mu \mathrm{m}$ double SUPOR filter configuration. In contrast, significant ${ }^{234} \mathrm{Th}$ activity was found on the bottom QMA filter, equivalent to $\sim 16 \%$ of the ${ }^{234} \mathrm{Th}$ activity on the top filter. When the ${ }^{234} \mathrm{Th}$ activity on the bottom filter is subtracted from the top filter, the ${ }^{234} \mathrm{Th}$ activity falls within the range of other filter types. It must be noted here that not all of the activity on the bottom QMA filter can be attributed to sorption because there is always a 

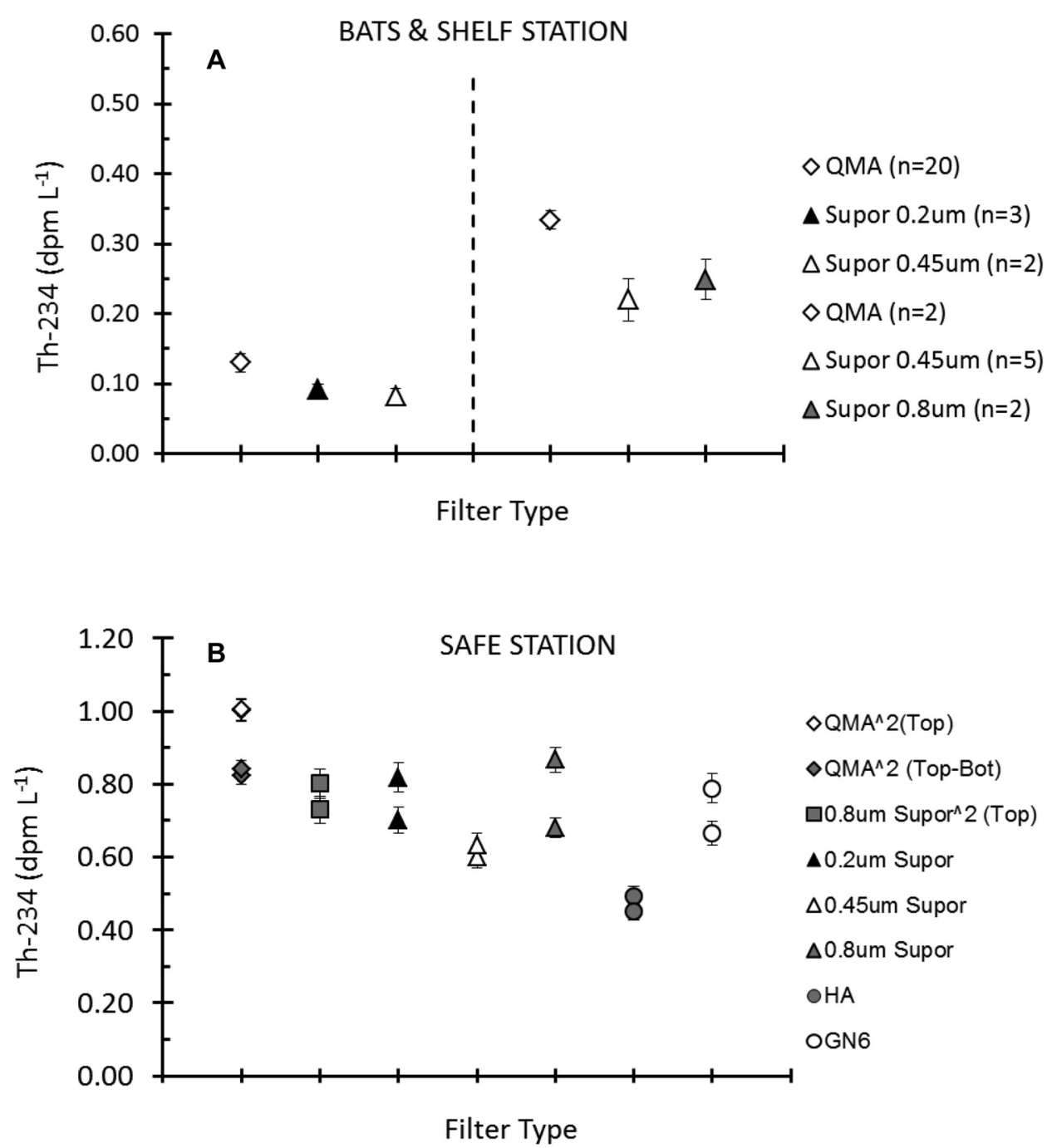

Fig. 6. Different filter types affecting 234Th activity on small particles. Two subsamples from each filter type $(n=2)$ is analyzed for SAFE station.

probability that some of the particles missed by the top filter could have been caught on the bottom filter. The lower than average activity on the HA filter is more difficult to explain. The HA filter is the least robust filter among those tested, and it is possible some cracks may have developed during pumping, which was missed during visual inspection after collection. The other possibility is that the filter was not loaded correctly leading to particle loss during collection.

\section{Flow-rate experiment}

The battery-operated McLane pumps are the most commonly used in situ pumps to collect size fractionated particle samples for ${ }^{234} \mathrm{Th}$ analysis. Historically, Challenger pumps were also used for filtering large water volumes for ${ }^{234} \mathrm{Th}$ measurements (e.g., JGOFS), but they are no longer available commercially. Hence, we focus solely on McLane type pumps. One important function of this pump is that it allows the operator to pre-define the minimum and maximum flow-rates within which the pump will operate. Depending on the model of the pump, the lowest rate at which the pump can operate is 2 or $4 \mathrm{~L} \mathrm{~min}^{-1}$, whereas the upper limit can be set to a maximum of 8 or $10 \mathrm{~L} \mathrm{~min}^{-1}$. To understand whether flow-rates impact particulate ${ }^{234} \mathrm{Th}$ samples, we took advantage of the eight pump rosette. Samples were collected simultaneously using all the eight pumps where each pump was set to operate within a specific range of flow-rates (e.g., 2-3 $\mathrm{L} \mathrm{min}^{-1}$ for pump 1, 3-4 $\mathrm{L} \min ^{-1}$ for pump 2, and so on).

In 2008, samples were collected at the SHELF shallow station where the pumps were grouped into two sets of four pumps each. One set was loaded with QMA filters and set to operate at $2-3,4-5,6-7$, or $7-8 \mathrm{~L} \mathrm{~min}^{-1}$. The other set was loaded with SUPOR filters $(0.45 \mu \mathrm{m})$ and operated at $4-5,5-6$, 6-7, and 7-8 $\mathrm{L} \mathrm{min}^{-1}$. The goal was to check whether there are any significant differences in ${ }^{234} \mathrm{Th}$ activity on particles collected on the screens $(>51 \mu \mathrm{m})$ due to the presence of the two different kinds of filters that follow in sequence, e.g., due to subtle changes in pressure, etc. 
No significant change in particulate ${ }^{234} \mathrm{Th}$ activity was observed beyond that associated with inter-pump variability of 8-16\%. The only exception was for the samples collected using the 7-8 L min'-1 flow rate, where the particulate samples had a significantly higher ${ }^{234} \mathrm{Th}$ activity than any other samples collected in the same cast. It is in fact the highest value recorded among all casts from this station. We attribute this high value to natural heterogeneity of suspended large particles in the water column. The more interesting outcome of this flow-rate experiment is the linear dependency $\left(r^{2}=0.92\right)$ between ${ }^{234} \mathrm{Th}$ activity on $>51 \mu \mathrm{m}$ particles and flow-rate (Fig. 7). The ${ }^{234} \mathrm{Th}$ activity on screens was found to decrease with increasing flowrates. While this trend can be explained by the fact that relatively fragile larger particles are prone to breakage when filtered at high flow-rates, the relatively narrow range of flow-rates (2-8 L min ${ }^{-1}$ ) over which this occurs is surprising.

In 2009, a similar experiment was conducted at the SAFe shallow station, where all the eight pumps had QMA filters downstream of the screens. The flow range was also expanded to a maximum of $9 \mathrm{~L} \mathrm{~min}^{-1}$. The results again indicate a linear
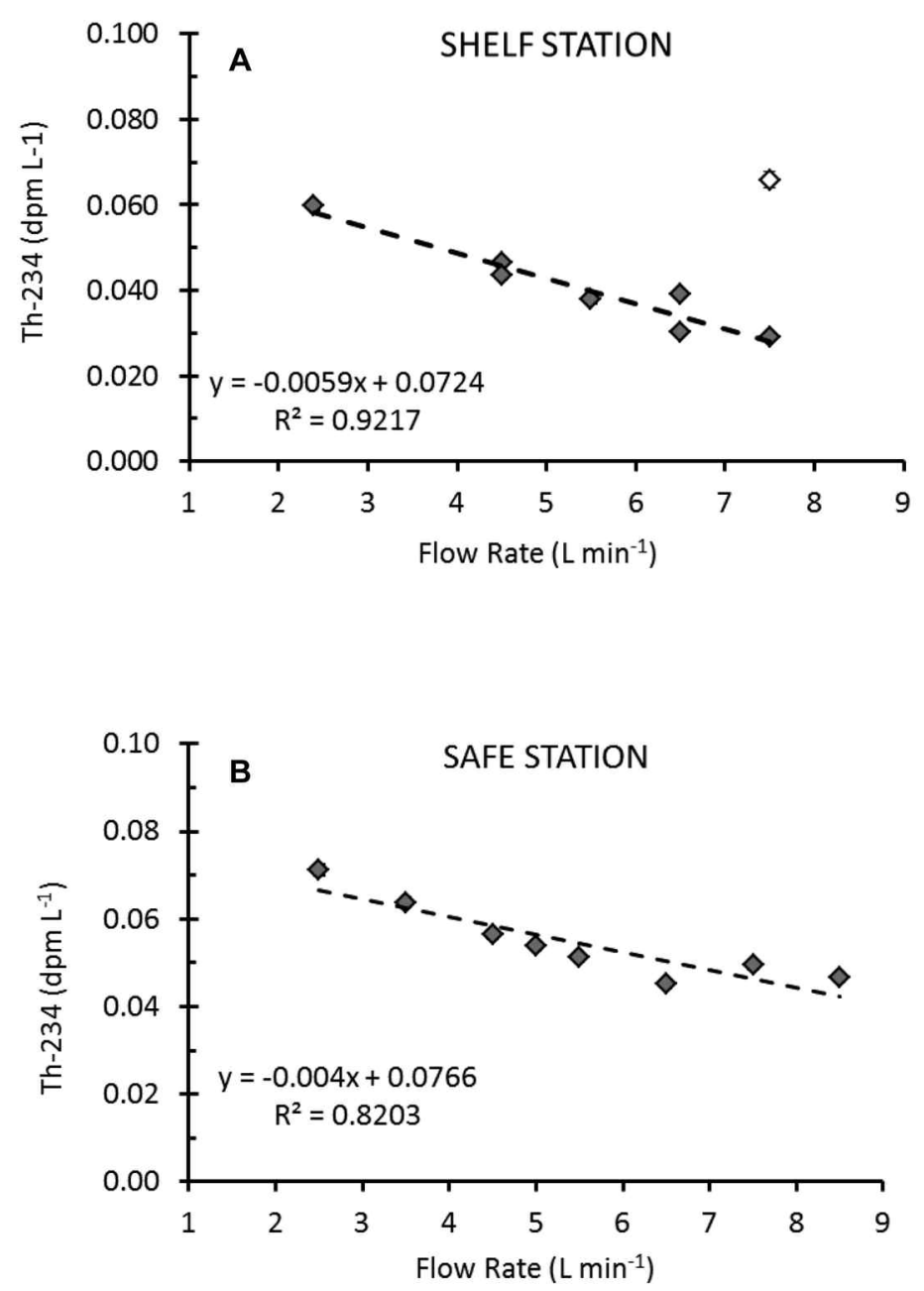

Fig. 7. Impact of flow rates on 234 Th activity in large particles. decrease $\left(r^{2}=0.82\right)$ in large particle ${ }^{234} \mathrm{Th}$ activity with increasing flow-rate (Fig. 7). When comparing the results between the SHELF and SAFe stations, it appears that the ${ }^{234} \mathrm{Th}$ activity is less sensitive to changes in flow-rates at SAFe, perhaps due to the differences in the nature of the particles present in the water column. For the small particles, no relationship between flow-rate and ${ }^{234} \mathrm{Th}$ activity was observed at either the SHELF or SAFe stations.

\section{Matrix type experiment}

One of the major drawbacks of $\beta$ counting, other than indiscriminate measurement of all $\beta$-emitters present in a sample, is the possible self-absorption-induced biases due to difference in particle characteristics and loading on filters (Rutgers van der Loeff and Moore 1999; Rutgers van der Loeff et al. 2006). To test possible matrix effects on altering $\beta$ counting efficiencies, particle samples from a wide range of geographic locations (ALOHA, K2, EDDIES, GEOTRACES) were analyzed. These filter samples were run directly on $\beta$ detectors in one laboratory to count for ${ }^{234} \mathrm{Th}$. These samples were subsequently dismounted and purified for ${ }^{234} \mathrm{Th}$ using column chemistry followed by electroplating on steel planchets. The steel planchets were again run on the $\beta$ detectors for ${ }^{234} \mathrm{Th}$ measurements. The activities of ${ }^{234} \mathrm{Th}$ were determined using well established efficiencies of ${ }^{234} \mathrm{Th}$ on steel planchets (using ${ }^{238} \mathrm{U}$ standard in equilibrium with ${ }^{234} \mathrm{Th}$ ) and accounting for column recoveries using a ${ }^{230} \mathrm{Th}$ yield monitor. Instrumental counts for filters measured directly (CPM) were plotted versus their activities measured (DPM) on steel planchets (Fig. 8). The relationship between CPM versus DPM, i.e., the slope of the linear fit, provides the efficiency for counting filters directly on the detector. The results indicate that collection region (and thus particle type), and filter type (QMA versus SUPOR) do not significantly affect detector efficiencies. The detectors also seem to be stable over long time periods given the $\sim 3 \mathrm{y}$ time span over which these samples were processed.

\section{Total ${ }^{234} \mathrm{Th}$ inter-calibration}

Intercalibration was carried out for total ${ }^{234} \mathrm{Th}$ in the water column only during 2009 cruise. Deep water samples were collected from SAFE station $(4000 \mathrm{~m})$ using trace-metal clean Goflo rosette while surface water was collected from SSB station using trace-metal clean intake system deployed off the side of the ship. For deep water station water approximately 200L of unfiltered water was collected in a plastic tank, acidified with $\mathrm{HNO}_{3}$ to $\mathrm{pH} \sim 2$ and then homogenized using a recirculating pump. In case of SSB station, water collected through the intake system was first passed through $1 \mu \mathrm{m}$ cartridge filter before being collected in the tank and then acidified to $\mathrm{pH} \sim 2$. Samples were collected in triplicate for each laboratory at both the stations. In order to reproduce the collection protocol for individual laboratories, samples were collected in containers provided by each of the participating laboratories. Thus sample volume varied from $2 \mathrm{~L}$ to $8 \mathrm{~L}$ depending on the collection protocol of the particular laboratory. Samples were analyzed by all laboratories within two to 4 weeks of collection. 

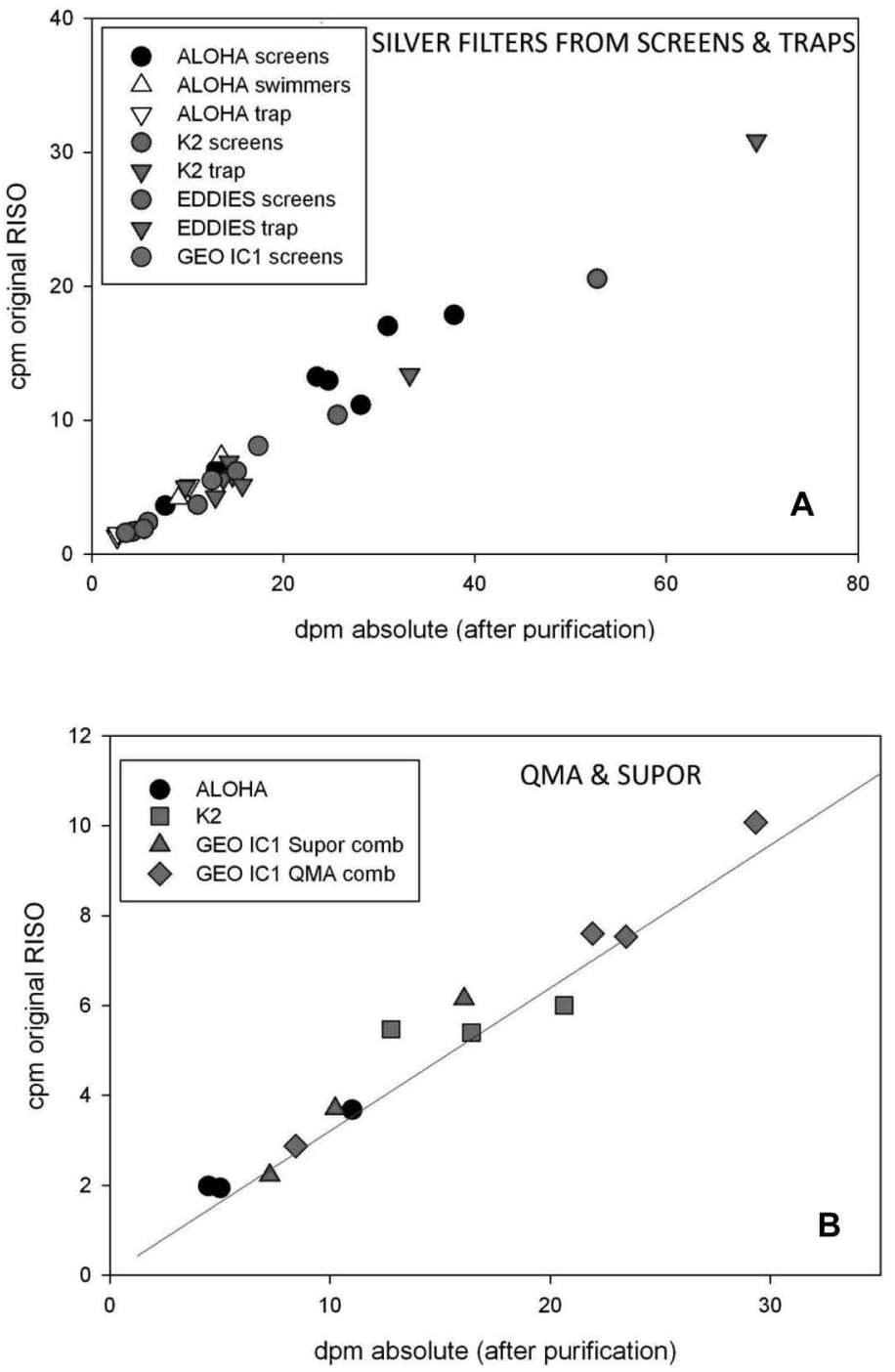

Fig. 8. Variability in efficiency of RISO counters for different particle types.

Laboratories followed their individual protocol for processing these ${ }^{234} \mathrm{Th}$ water samples and reported their data decay and in-growth corrected to the time of collection. All laboratories followed their own version of small volume ${ }^{234} \mathrm{Th}$ measurement technique (Benitez-Nelson et al. 2001a; Pike et al. 2005). Briefly, ${ }^{234} \mathrm{Th}$ was co-precipitated using $\mathrm{MnO}_{2}$. The $\mathrm{MnO}_{2}$ precipitate was filtered, dried, mounted, and directly run on lowlevel $\beta$ detectors. The process efficiency was determined by using ${ }^{230} \mathrm{Th}$ spike to quantify recovery using ICPMS or $\alpha$ detector. One laboratory used double co-precipitation technique where the samples were co-precipitated a second time to cross check for recovery while another laboratory used an estimated recovery estimate from prior experiments. Only one laboratory carried out column chemistry to isolate ${ }^{234} \mathrm{Th}$ before counting, following the method outlined in Waples et al. (2003). Depending on the laboratory, the sample background was either determined by recounting the samples after waiting for
6 months or the samples were periodically counted to construct the decay curve and extrapolate the background value.

Due to the time delay between sample collection and processing, significant corrections had to be made to the final data to account for ingrowth of ${ }^{234} \mathrm{Th}$ from its parent ${ }^{238} \mathrm{U}$, present in the water samples (see Rutgers van der Loeff et al. 2006 for details on in-growth corrections). To carry out ingrowth corrections, ${ }^{238} \mathrm{U}$ activities were determined from salinity measurements of $34.6746 \pm 0.0038$ and $33.9201 \pm 0.0103$ from SAFE and SBB water samples, respectively. The ${ }^{238} \mathrm{U}$-salinity relationship of ${ }^{238} \mathrm{U}\left(\mathrm{dpm} \mathrm{L} \mathrm{L}^{-1}\right)=0.0704 *$ salinity (Chen et al. 1986) was used by all laboratories to calculate ${ }^{238} \mathrm{U}$ activity in the water samples. To understand if in-growth correction had any effect on the final numbers, an additional set of samples were processed using the $\mathrm{MnO}_{2}$ technique and counted onboard by one laboratory (WHOI), immediately after collection and thus had a relatively small in-growth correction applied to it. No difference in activity was found between the sample set analyzed on-board and the sample set analyzed back in laboratory after proper decay and ingrowth corrections were made (Rutgers van der Loeff et al. 2006).

The inter-calibration results for deep water samples show good agreement amongst laboratories, i.e., the reported values from all laboratories are within 95\% confidence limit with exception of one laboratory (Fig. 9). It must be noted, however, that error bars shown for the laboratories represent the standard deviation between triplicate samples and not the absolute error, which is usually below 5\% for all deep water samples. The mean reported ${ }^{234} \mathrm{Th}$ activity for all laboratories was 2.433 $\pm 0.035 \mathrm{dpm} \mathrm{L}^{-1}$ (dashed line in Fig. 9). This is statistically similar to the expected value of $2.4418 \pm 0.0003 \mathrm{dpm} \mathrm{L}^{-1}$, calculated assuming secular equilibrium and using the salinity data mentioned above. The intercalibration results for the SSB surface water samples indicate an average ${ }^{234} \mathrm{Th}$ activity of $1.082 \pm$ $0.042 \mathrm{dpm} \mathrm{L}^{-1}$ for all laboratories (Fig. 9). The error bars shown in Fig. 9 represent the standard deviation among the triplicate samples while the absolute error on individual samples varied between $4 \%$ to $10 \%$ for shallow water samples. However the agreement amongst different laboratories is not as robust as deep water samples, with results from two laboratories falling beyond the 95\% confidence level. In addition, results from three more laboratories fall within the 95\% confidence limit only when we take into account their range in variability from the triplicate analysis. The two major causes for this high variability could be the low activity of these samples and the time lag (2-4 weeks) between sample collection and processing, which resulted in a larger in-growth correction and simultaneous decrease in initial ${ }^{234} \mathrm{Th}$ activity of the sample. For the SBB samples, we estimated that the in-growth correction represents approximately $10 \%, 50 \%$, and $190 \%$ of the initial ${ }^{234} \mathrm{Th}$ activity at collection if water samples were processed 1 day, 1 week or 3 weeks after collection respectively. As such, in the case of water samples with low initial activity, the longer the wait time between collection and processing, the smaller the difference 

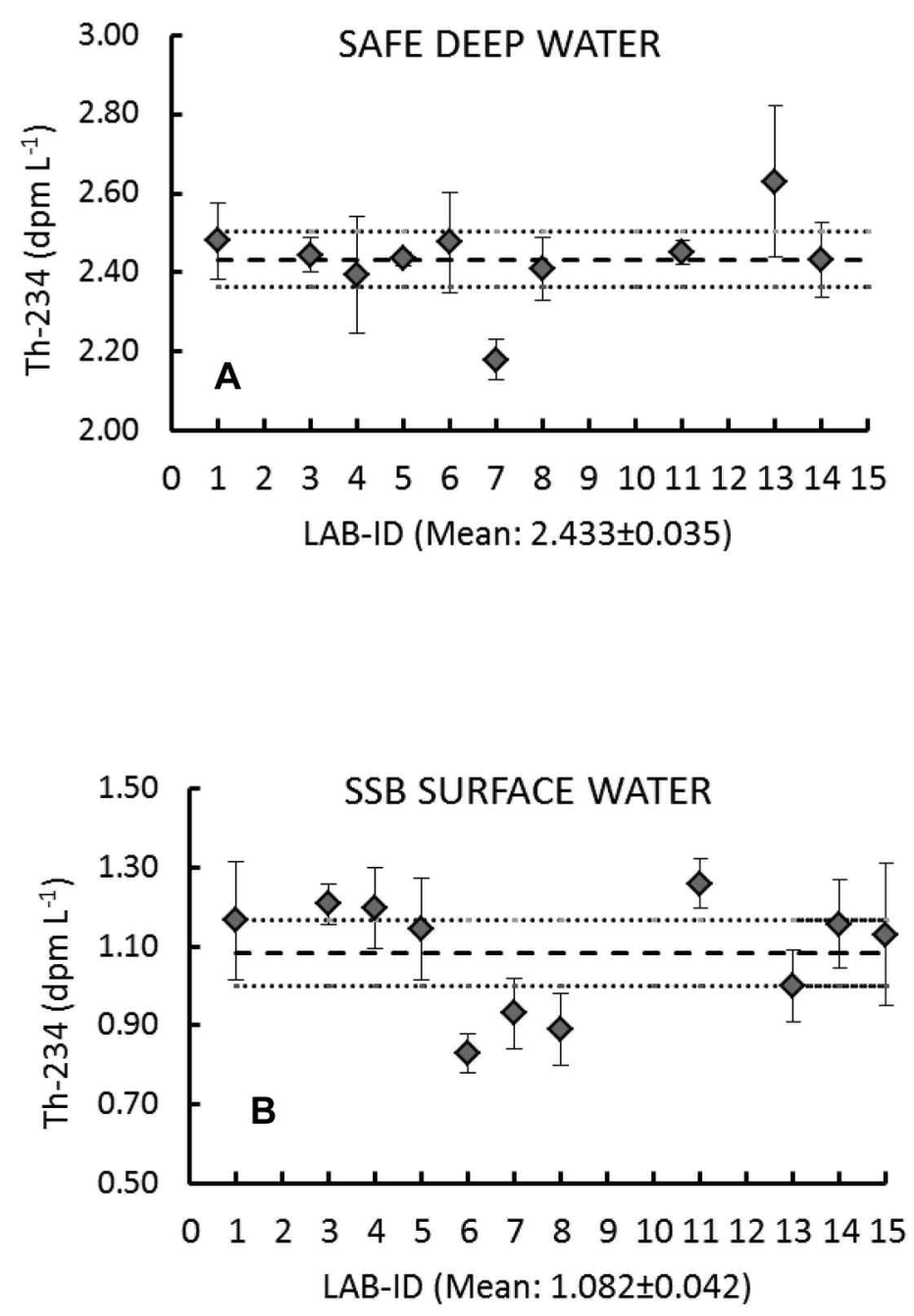

Fig. 9. Intercalibration results for total 234Th. The error bar represents the standard deviation for the triplicate analysis carried out by each lab. The dotted lines represent $95 \%$ confidence interval, and dashed line represents the mean value.

between the total ${ }^{234} \mathrm{Th}$ activity (sum of residual ${ }^{234} \mathrm{Th}$ present after decay and new ${ }^{234} \mathrm{Th}$ produced from ingrowth) and the ${ }^{234} \mathrm{Th}$ in-growth correction. Thus the signal for initial ${ }^{234} \mathrm{Th}$ activity present in the sample becomes an increasingly smaller number produced by difference of two large numbers, resulting in a large percent error.

\section{Discussion}

Given the inter-pump and inter-filter variability, the interlaboratory variability for both small and large particles appears to be reasonable. Overall, results from no laboratory was found to be consistently different from the mean ${ }^{234} \mathrm{Th}$ activity reported for the inter-calibration exercise conducted on samples from stations with different particle types from the Atlantic (2008) and the Pacific (2009). Whereas individual laboratories sometimes reported data beyond the $95 \%$ confidence limit, these differences were inconsistent between particle type and sampling cruise. There are at least two possibilities that can cause such a difference for a single laboratory in different years (i) the absolute detector efficiencies changed between the $2 \mathrm{y}$ and/or (ii) the changes were due to different particle types, which could have altered the effective efficiencies of the detector. However the possibility of particle type affecting detector efficiencies seems low in light of the results shown above. A third possibility that may explain deviations from the mean for the two sampling cruises is the batch to batch variability in thickness of the aluminum foil used to premount these filters. Although care was taken to use the same brand of aluminum foil for both years, batch-to-batch variability cannot be ruled out, with the possibility of one batch of aluminum foil being more representative of the foils used by the laboratories in question for calibration in 1 year versus the other. Although the exact cause remains uncertain, we would like to recommend using the same kind of aluminum foil for samples to keep results consistent within a laboratory.

The other important exercise in the ${ }^{234} \mathrm{Th}$ inter-calibration was to evaluate the variables associated with collecting large volume particulate samples. The results from filter-type experiments reiterate the fact that QMA filters suffer from sorption blanks, which need to be included when measuring ${ }^{234} \mathrm{Th}$ activity on small particles. One possible solution is to pump large volumes of water through the filter such that ${ }^{234} \mathrm{Th}$ adsorbed on particles is reduced to a negligible fraction relative to the total ${ }^{234} \mathrm{Th}$ on the filter. However availability of wire-time for pumping for extended periods may not be an option. Another possible solution therefore is to use two QMA filters placed on top of one another, where the bottom QMA can be considered an sorption blank. Although it should be noted that the pore size on these filters are nominal, and there is always a possibility that some particles not caught on the top filter may be captured by the bottom filter. Another important factor to keep in mind before using such a correction factor is the inherent assumption in this approach that assumes dissolved thorium is all in the same chemical form and so the fraction absorbed on the filter is same in both cases, as well as the fact that particles on the top filter do not interfere with the sorption. Despite the sorption issues with the QMA filters, we find it difficult to recommend any other filter type because of the advantages associated with QMA, viz., simultaneous measurement of different elements $(\mathrm{C}, \mathrm{N})$ on the same filter, filtering capability for large volumes of water (without clogging), and ease of handling, subsampling, and homogeneous distribution of material across the filter. Nonetheless, if only particulate ${ }^{234} \mathrm{Th}$ activity needs to be measured, both SUPOR and GN6 filters provide viable options with PALL mixed cellulose ester filter being the easier of the two in terms of subsampling for punches. However in terms of trace metal analysis the SUPOR filters are found to be most appropriate because of its high level of recovery, faster filtration rate, low blanks, and ease of handling (Smith et al. 1993; Cullen and Sherrell 1999; Kiene and Linn 1999). Thus we rec- 
ommend using QMA filters when ${ }^{234} \mathrm{Th}$ is applied as a tracer of POC flux in the water column and to use SUPOR filters when ${ }^{234} \mathrm{Th}$ is being applied as a tracer of trace metal flux and cycling in the water column. In studies where ${ }^{234} \mathrm{Th}$ needs to be applied as a tracer for both POC and trace metals, the choice of filter can be solved by modifying the single filter holder McLane pumps into dual filter-holder pumps where one filter holder is loaded with QMA filter and the other filter holder is loaded with SUPOR filter. In the recently concluded Atlantic GEOTRACES section, this approach was successfully applied to simultaneous collect large volume particle samples for POC and TEI analysis using QMA and SUPOR filters, respectively. Apart from filter type, we found pump flow-rates impacting the collection of large particles. If pumping rates are lowered, the likelihood of retaining large particles on the screen increases, although sample volumes typically ranging from 400-800 L will take much longer time to filter. However it must be noted that most of the McLane in situ pumps presently in operation are fitted with a 4-8 $\mathrm{L} \mathrm{min}^{-1}$ pump head, and setting the maximum allowable flow rate of the pump close to its operational lower limit of $4 \mathrm{~L} \mathrm{~min}^{-1}$ can cause the pump to shut off prematurely. In this regard, maximum pumping rates between 5-6 $\mathrm{L} \mathrm{min}^{-1}$ appear to be a reasonable compromise between time and material loss. Thus under ideal conditions, the recommended flow rate is $5 \mathrm{~L}$ $\mathrm{min}^{-1}$. In situations where time and/or volume filtered is an issue, it is recommended not to go beyond $6 \mathrm{~L} \mathrm{~min}^{-1}$ flow rate to preserve the sample integrity. It must be noted here that 5 $\mathrm{L} \mathrm{min}^{-1}$ flow rate is equivalent to vacuum filtering (in terms of volume filtered per unit area of filter per unit time), a typical $3 \mathrm{~L}$ bottle POC sample in $25 \mathrm{~min}$ whereas $6 \mathrm{~L} \mathrm{~min}^{-1}$ flow rate is equivalent to filtering the same in 20 min using a $25 \mathrm{~mm}$ filter (assumed active area of $21 \mathrm{~mm}$ ).

Total ${ }^{234} \mathrm{Th}$ inter-calibration results for deep water samples showed good agreement amongst laboratories. The mean

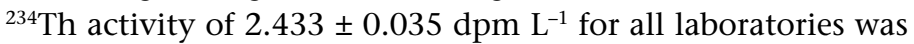
also found to be in very good agreement with the salinity

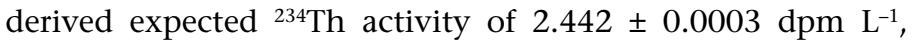
assuming secular equilibrium. However in comparison, the ${ }^{234} \mathrm{Th}$ activities from SBB surface water had much more variability because of lower initial activity and large ingrowth corrections from ${ }^{238} \mathrm{U}$. It is thus recommended to keep the time between collection and filtering to a minimum in order to keep in-growth corrections to a minimum. This also reduces the error associated with the uncertainties in both salinity measurements and the ${ }^{238} \mathrm{U}$-salinity relationship as the error is propagated when ingrowth corrections are made. Recent reevaluation of the ${ }^{238} \mathrm{U}$-salinity relationship (Owens et al. 2011) indicates a difference of $1.3 \%$ with respect to the more established relationship by Chen et al. 1986, which used a smaller dataset than the recent work. This difference of $1.3 \%$ may appear insignificant, but in reality can translate to greater than $5 \%$ change in ${ }^{234} \mathrm{Th}$ fluxes if ${ }^{234} \mathrm{Th} /{ }^{238} \mathrm{U} \sim 1$. Thus, it is important to understand the limitation of this relation and propagate the associated errors appropriately.

Overall, results from the current intercalibration effort indicate that maximum variability can be expected in a high particle environment, which in this study is at the SBB station where the a standard error for the mean of the results from all laboratories is $4 \%$ of total ${ }^{234} \mathrm{Th}$ activity and $8 \%$ for ${ }^{234} \mathrm{Th}$ activity on large particles. To use ${ }^{234} \mathrm{Th}$ as a proxy for POC export, we have to multiply the depth integrated ${ }^{234} \mathrm{Th}$ deficit with the $\mathrm{C} /{ }^{234} \mathrm{Th}$ ratio on large particles. Thus, for a station like SBB, where fluxes can be measured from a typical six point profile in the upper $150 \mathrm{~m}$ of the water column, we can expect a maximum of $15 \%$ variability in the estimates between different laboratories based on our inter-calibration results. In comparison, we can expect good agreement in flux measurements amongst laboratories in an open ocean setting with lower ${ }^{234}$ Th deficiency.

\section{Acknowledgments}

We would like to thank the captain and crew of R/V Knorr. Thanks to the Café Thorium members-Sharmila Pal and Kelsey Collasius-for their help with sample collection and processing. Geoff Smith and Ken Bruland deserve special thanks for allowing us to use their mixing tanks and fish surface sample collection setup. Phoebe Lam and Robert Sherrell provided some important suggestions and insights during the planning phase of this project. The WHOI metal shop deserves special mention for translating our idea of a pump rosette into reality. This research is funded by NSF Chemical Oceanography program. LM will like to thank Fisheries and Oceans Canada for support. PM is supported through ICREA Academia funded by Generalitat de Catalunya. The International Atomic Energy Agency is grateful to the Government of the Principality of Monaco for the support provided to its Environment Laboratories. This paper is part of the Intercalibration in Chemical Oceanography special issue of Limnology and Oceanography: Methods that was supported by funding from the U.S. National Science Foundation, Chemical Oceanography Program.

\section{References}

Benitez-Nelson, C. R., and others. 2001a. Testing a new smallvolume technique for determining thorium-234 in seawater. J. Radioanal. Nucl. Chem. 248(3):795-799 [doi:10.1023/A:1010621618652].

, K. O. Buesseler, D. M. Karl, and J. E. Andrews. 2001b. A time-series study of particulate matter export in the North Pacific Subtropical Gyre based on ${ }^{234} \mathrm{Th}:{ }^{238} \mathrm{U}$ disequilibrium. Deep-Sea Res. I 48:2595-2611 [doi:10.1016/S09670637(01)00032-2].

—, and W. S. Moore. 2006. Future applications of ${ }^{234} \mathrm{Th}$ in aquatic ecosystems. Mar. Chem. 100:163-165 [doi:10.1016/ j.marchem.2005.10.010].

Bhat, S. G., and others. 1969. ${ }^{234} \mathrm{Th} /{ }^{238} \mathrm{U}$ ratios in the ocean. Earth Planet. Sci. Lett. 5:483-491 [doi:10.1016/S0012-821X (68)80083-4]. 
Buesseler, K., and others. 1992. Carbon and nitrogen export during the JGOFS North Atlantic Bloom Experiment estimated from 234Th:238U disequilibria. Deep-Sea Res. I 39:1115-1137 [doi:10.1016/0198-0149(92)90060-7].

Buesseler, K. O., L. Ball, J. Andrews, C. Benitez-Nelson, R. Belastock, F. Chai, and Y. Chao. 1998. Upper ocean export of particulate organic carbon in the Arabian Sea derived from thorium-234. Deep-Sea Res. II, Arabian Sea 45:2461-2487.

- , and others. 2001. An intercomparison of small- and large-volume techniques for thorium-234 in seawater. Mar. Chem. 74:15-28 [doi:10.1016/S0304-4203(00)00092-X].

_, and others. 2006. An assessment of particulate organic carbon to thorium-234 ratios in the ocean and their impact on the application of 234Th as a POC flux proxy. Mar. Chem. 100(3-4):213-233 [doi:10.1016/ j.marchem.2005.10.013].

—, and others. 2008. Particle fluxes associated with mesoscale eddies in the Sargasso Sea. Deep-Sea Res. II 55:1426-1444.

Chen, J. H., and others. 1986. ${ }^{238} \mathrm{U},{ }^{234} \mathrm{U}$ and ${ }^{232} \mathrm{Th}$ in seawater. Earth Planet. Sci. Lett. 80:241-251 [doi:10.1016/0012821X(86)90108-1].

Coale, K. H., and K. W. Bruland. 1985. ${ }^{234} \mathrm{Th}:{ }^{238} \mathrm{U}$ disequilibria within the California Current. Limnol. Oceanogr. 30:22-33 [doi:10.4319/lo.1985.30.1.0022].

Cullen, J. T., and R. M. Sherrell. 1999. Techniques for determination of trace metals in small samples of size-fractionated particulate matter: phytoplankton metals off central California. Mar. Chem. 67:233-247 [doi:10.1016/S03044203(99)00060-2].

Gustafsson, Ö., P. M. Gschwend, and K. O. Buessler. 1997a. Settling removal rates of PCBs into the Northwestern Atlantic derived from 238U-234Th disequilibria. Env. Sci. Technol. 31:3544-3550 [doi:10.1021/es970299u].

- - , and 1997b. Using ${ }^{234} \mathrm{Th}$ disequilibria to estimate the vertical removal rates of polycyclic aromatic hydrocarbons from the surface ocean. Mar. Chem.57:11-23 [doi:10.1016/S0304-4203(97)00011-X].

Henderson, G., and others. 2007. GEOTRACES-An international study of the global marine biogeochemical cycles of trace elements and their isotopes. Chem. Erde Geochem. 67:85-131 [doi:10.1016/j.chemer.2007.02.001].

Johnson, K. S., and others. 2007. Developing standards for dissolved iron in seawater. EOS Trans. 88:131-132.

Kiene, R. P., and L. Linn. 1999. Filter-type and sample han- dling affect determination of organic substrate uptake by bacterioplankton. Aquat. Microb. Ecol. 19:311-321 [doi:10.3354/ame017311].

Maiti, K., C. and others. 2010. Insights into particle formation and remineralization using the short-lived radionuclide, Thoruim-234. Geophys. Res. Lett. 37(L15608) [doi:10.1029/2010GL044063].

Owens, S. A., K. O. Buesseler, and K. W. W. Sims. 2011. Re-evaluating the 238U-salinity relationship in seawater: Implications for the ${ }^{238} \mathrm{U}-{ }^{234} \mathrm{Th}$ disequilibrium method. Mar. Chem. 127:31-39 [doi:10.1016/j.marchem.2011.07.005].

Pike, S. M., and others. 2005. Quantification of ${ }^{234}$ Th recovery in small volume sea water samples by inductively coupled plasma-mass spectrometry. J. Radioanal. Nucl. Chem. 263(2):355-360.

Rutgers van der Loeff, M. M., and W. S. Moore. 1999. Determination of natural radioactive tracers, Chapter 13, p. 365-397. In K. Grasshoff, M. Ehrhardt, and K. Kremling [Eds.], Methods of seawater analysis, third ed. Verlag Chemie [doi:10.1002/9783527613984.ch13].

Rutgers van der Loeff, M. R., M. M. Sarin, and others. 2006. A review of present techniques and methodological advances in analyzing ${ }^{234} \mathrm{Th}$ in aquatic systems. Mar. Chem. 100(34):190-212 [doi:10.1016/j.marchem.2005.10.012].

Smith, L., and others. 1993. Comparison of membrane filters for recovery of Legionellae from water samples. Appl. Environ. Microbiol. 59(1):344-346.

Taylor, J. K. 1987. Quality assurance of chemical measurements. Lewis Publishers.

Waples, J. T, K. A. Orlandini, and others. 2003. Measuring low concentrations of Th-234 in water and sediment. Mar. Chem. 80(4): 265-281 [doi:10.1016/S0304-4203(02)00118-4].

- C. R. Benitez-Nelson, N. Savoye, M. Rutgers van der Loeff, M. Baskaran, and Ö. Gustafsson. 2006. An introduction to the application and future use of ${ }^{234} \mathrm{Th}$ in aquatic systems. Mar. Chem. 100:166-189 [doi:10.1016/j.marchem.2005.10.011].

Weinstein, S. E., and S. B. Moran. 2005. Vertical flux of particulate $\mathrm{Al}, \mathrm{Fe}, \mathrm{Pb}$, and $\mathrm{Ba}$ from the upper ocean estimated from Th-234/U-238 disequilibria. Deep-Sea Res. I 52:14771488 [doi:10.1016/j.dsr.2005.03.008].

Submitted 9 September 2011 Revised 4 April 2012 Accepted 6 May 2012 